International Journal of Linguistics, Literature and Translation

ISSN: 2617-0299 (Online); ISSN: 2708-0099 (Print)

DOI: $10.32996 /$ ijllt

Journal Homepage: www.al-kindipublisher.com/index.php/ijltt

IJLLT

\title{
Rapport Management in Online Racial Humor
}

\author{
Taghreed Abdulasalam ${ }^{1} \square$ and Istqlal Hassan Ja'afar ${ }^{2}$ \\ ${ }^{1}$ Assistant professor, Department of English language and Linguistics, College of Arts, Mustansirya University, Baghdad, Iraq \\ ${ }^{2}$ Department of English language and Linguistics, College of Arts, Mustansirya University, Baghdad, Iraq \\ $\square$ Corresponding Author: Taghreed Abdulasalam, E-mail: totaaliroro1993@gmail.com
}

ARTICLE INFORMATION ABSTRACT

Received: 16 October 2021

Accepted: 12 November 2021

Published: 30 November 2021

DOI: $10.32996 /$ ijllt.2021.4.11.11

\section{KEYWORDS}

Racial jokes, humor, rapport, (im)politeness, interpersonal
The present paper aims to investigate how racial humor, posted on Twitter affects rapport between interlocutors at both the interpersonal and intercommoned levels. Thus, the main problem this thesis attempt to address is English as a Lingua Franca (ELF) users' potential lack of awareness of the racially sensitive issues and how to deal with them in (online) intercultural communication. The paper aims to advance the understanding as to how the social and technological affordances of the medium (Herring, 2007) can shape the contexts in which racial humor is morally perceived and attitudinally assessed (in terms of politeness and impoliteness) by the audience on Twitter. After in-depth reading and a systematic coding process, a dataset totaling (312) racial jokes and (956) responses from various users, racial jokes circulated online were found to orient rapport either towards challenge or enhancement These two rapportorientations were found to be (im)politeness-implicative on two different levels; the interpersonal level between the account administrator and his/her followers, and the societal level between social groups targeted by racial humor and the dominant social group in the society.

\section{Introduction}

With the rise of using social media to communicate humorous content, many accounts were created on Twitter to circulate different types of jokes to attract different followers. Interestingly, many of these accounts were specialized in racial jokes. Circulating racial jokes can typically have two different functions: reinforcing racial stereotypes or alternatively resisting these stereotypes through raising awareness about their negative social impacts in a sarcastic setting. Hughes (2003: 1443) defines racial jokes as that type of jokes which is based on aspects of expressing feelings, moods, opinions, and attitudes towards certain social issues, with the goal of developing in-group relations, mitigating tension among individuals of the same association, enhance self-identification and solidarity.

The main problem this study attempt to address is English as a Lingua Franca (ELF) users' potential lack of awareness of the racially sensitive issues and how to deal with them in (online) intercultural communication. The paper aims to advance the understanding as to how the social and technological affordances of the medium (Herring, 2007) can shape the contexts in which racial humor is morally perceived and attitudinally assessed (in terms of politeness and impoliteness) by the audience on Twitter. Within this context, the paper attempts to answer the following research question:

1. How does social humor affect rapport between interlocutors on Twitter?

2. What types of impacts Twitter affordances can have on rapport management?

\section{Theoretical Background}

\subsection{Racial Joke Genre}

Different forms and functions of humor can be distinguished. Certain forms and functions of humor can be distinguished as clearly identifiable as communicative genres. One of these genres is the genre of joke. From a textual perspective, Ritchie (2004: 15) defines a joke as a relatively brief text whose basic purpose is to trigger a distracted reaction within its readers/hearers, and that is usually

Copyright: (c) 2021 the Author(s). This article is an open access article distributed under the terms and conditions of the Creative Commons Attribution (CC-BY) 4.0 license (https://creativecommons.org/licenses/by/4.0/). Published by Al-Kindi Centre for Research and Development, London, United Kingdom. 
repeatable in a wider range of conditions. Within the domain of linguistics, it was found that jokes make use of linguistic ambiguity and there seems a frame of jokes which recognizes itself not by actions or events, but relies on particular linguistic traits or features of language for their effect. A special form of jokes can be described as highly language-dependent. Such a form of joke is commonly known as "pun", (Zabalbeascoa, 1996: 253).

Furthermore, Shade (1994: 3) assumes that certain jokes can be anything uttered to provoke a funny attitude, but it has to have certain features, such as; multiple senses of words, idioms, and metaphors; vague; incongruity, and unpredicted shift of perspective.

A special type of joke is known as a racial joke. They have a long history, especially in the United States. Billings (2005: 31) and Willis (2005: 131) state that it has served both as "an oppressive and uplifting element" for racial minority groups. As social productions, jokes rely heavily on context for success or failure. Whoever laughs at racial jokes usually relies on who is telling them. It has been argued that suitable laughter at an ethnic joke is contingent upon an in-group member telling it, to acknowledge that there are peculiarities within which the joke is being told.

Hughes (2003: 1443) states that during the nineteenth-century racial jokes represented two primary social functions. First, the flurry of jokes that targeted newly arrived immigrant associations reflected the concern of white Americans that they could lose their privileged social position. Such jokes typically described immigrants as stupid, dirty, or lazy, and focused their inalterable differences. Second, racial jokes are usually highlighted on current social concerns. For example, during the Industrial Revolution, entrepreneurs succeeded by constantly evolving with the furious pace of technology.

From a genre perspective, jokes have special linguistic, textual, and functional properties. Attardo (2001: 61-62) states that jokes can usually be described as brief, easy together, and painful stories that are informed for the purpose of entertaining any addresser. $\mathrm{He}$ (ibid) distinguishes two types of jokes: narrative jokes/canned Jokes and conversational jokes. Narrative jokes/canned Jokes are usually informed by narrators who present the jokes with the announcement of the humorous nature of the forthcoming turn. They are "rehearsed" i.e., they can be heard or made by the narrators before telling. They are also normally separated from the situation in that they are informed. Alternatively, interactional jokes can be told as if an ordered part in communication, without prefixing. These jokes are performed by the tellers and are quite context-dependent.

\subsection{Racial Jokes on Social Media}

Since its inception, social media have revolutionized communication across the globe both in terms of quality and quantity. Social media are now the most crucial and biggest means of communication and information exchange source. Users write down everything concerning their life, practices, relationships, and also their emotions. Social networks are websites on the "Internet" that bring individuals together in central locations to talk, exchange thoughts and interests, and make friends, (Teng-Sheng, 2010: 210).

The type of communication instantiated on social media is called "computer-mediated communication". Computer-mediated communication is usually viewed as a tool of distributing data, increasing institutional efficiency, generating electronic democracy, as well as challenging classical hierarchies (Baym, 1995: online). The current term can be described, by Metz (1994: 32), as any interactional manners among people, mediated through a computer or smartphones, not simply as a means but as contexts by which people can interact.

Social media users often communicate via verbal language, as they normally print on keyboards and read just like texts on computer screens. This effort is facilitated by the fact that people engage in socially meaningful, including humorous, activities online in a way that typically leaves a textual trace (Herring, 2004: 338). Posting and circulating racial jokes on social media is heavily influenced by the medium and situational affordances provided by the online platform used. These affordances maynot only influence how these jokes are posted and circulated but, more importantly, how they are produced and interpreted in an online context. Consequently, two forms of frames can be observed in terms of interaction: the frame of one-to-one interaction that is active recipient, i.e. certain follower, as for frame of one to many that are passive recipients, i.e. followers in general. Culpeper, et al. (2017: 785) mention that many factors of communicating online have an effect on the individual strategies are chosen in the ways that one can interpret (im)politeness. Such elements are explained as follows:

- Synchronous versus Asynchronous: recipient(s) and the sender should be present simultaneously. An individual's typing is transferred to the screen direction of the other one or one's. Messaging systems do not store messages but it is more temporal.

- Private-Oriented Networks Versus Public-Oriented Networks: In CMC, Perceptions of impoliteness are influenced by the participation structures deep-rooted in various media. 
- Relational Versus Task-Oriented: any media format can be task-oriented or relational. Although Facebook started as a way to associate with one another "relation-oriented", for instance, businesses now frequently utilize Facebook pages to enhance their services or products "task-oriented".

- Interaction-Focused Versus Declaration-Focused: platforms are declaration-focused since they permit users to 'pin' images and photos to a board and let others view what they have pinned.

- Anonymity: Haines (2014: 1) mentions that anonymity is one of the significant tools that is ensuring free exchanges of ideas via encouraging the expression of minority views.

- Longevity: Culpeper, et al. (2017: 790) affirm that one of theclear differences between CMC and face-to-face communication is that it is usually 'out there' for good-and consciousness of such factor can impact both individuals' production and perceptions of (im)politeness.

- CMC versus Face-to-face Communication: Begley (2004: 63) maintains that face-to-face communication denotes a conversation that an individual has whereas being face to face within the other party.

Thus, the next two sections will explore how the technological and situational/social affordances of the platform under scrutiny in this paper, i.e. Twitter, can affect rapport between interlocutors in the setting of production and reception of racial jokes.

\subsection{Rapport Management Theory}

Rapport management theory provides a conceptual framework that accounts for a wide range of relational phenomenon in communication, with a focus on the face, identity, and (im)politeness. This framework is suggested by Spencer-Oatey (2008). Rapport management theory focuses on the social and contextual factors as well as a certain cognitive element, influencing the goals and social rights (Spencer-Oatey, 2002). In the current theory, rapport denotes the subjective perception of individuals in their relationship of stability-fluctuation, harmony-disharmony, warmth-hostility. The perception of rapport is influenced by three interrelated potential factors: face sensitivities, social rights and involvements, and interactional aims.

- Face sensitivities

The concept of face is first developed by Goffman (1976) in his attempt to understand how social structures are (re)produced in social interactions. Goffman (1976: 1967) defines face as "the positive social value a person effectively claims for himself by the line others assume he has taken during a particular contact".

- Rights and obligations

Spencer-Oatey (2008) maintains that if people's manner expectations spring from social rights and obligations are not encountered within a conversation. There might be outcomes for the management of rapport.

- Interactional Goals

Locher (2008) claims that people have their own 'interpersonal goals' in conversation. They are basically concerned with what the interlocutor wants to achieve through their conversation.

\section{4 (Im)politeness, Power and Solidarity}

Politeness deals with what an individual ought to do and what he/she ought not to do. It is enticing to assume that there are tenets that describe what manner is to be aimed for and what is avoided and that these tenets have causal roles in performing good manner, (Allott, 2010: 142-143). As for impoliteness, Culpeper (2011: 23) where he defined impoliteness as "a negative attitude towards specific behaviors occurring in specific contexts. It is sustained by expectations, desires and /or beliefs about social organization, including, in particular, how one person's or a group's identities are mediated by others in interaction".

Culpeper, et al. (2017: 119) mention that 'power' and 'solidarity" can be described as normal words which are utilized as technical concepts in researches on human interaction. He (ibid) add that despite there being no acceptance of what theoretical components of those technical concepts must be, their significance is usually taken for granted in pragmatics, sociolinguistics, and social psychology.

The concept of power refers to the ability of individuals to influence other people's conditions. It can be described as 'the possibilities of assuming one's will on other individuals', (Holmes, 1995:17). Power does not necessarily require physical force; it can be exercised through language. In this regard, Alrikabi (2014) maintains that power involves many aspects or types of utilizing techniques being practiced, like, denial, lying, rationalization, diversion, minimization, shaming, and evasion.

Consequently, Fishman (2012: 123) explicates that power reflects the relationship between two individuals that cannot be alternated. Power may have based on wealth, age, physical strength, a function on the family, state, or army. Liu, et al. (2014: 67) 
assert that past literature shows that the grounds of power are often interrelated, i.e., they are interfering with each other which is utilized in combinations. However, the following figure (1) will illustrate the power dimension:

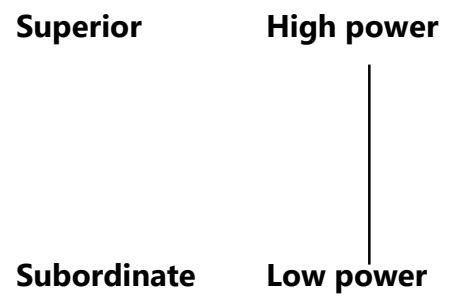

Figure (1) Power dimension (Adapted from Holmes, 1995:17)

The concept of power is also different but related to that of solidarity. According to Culpeper, et al. (2017: 119), 'solidarity' or 'social distance' can be thought of as an appearance of an identical social relationship among individuals with reference to some related aspects of their social relationships.

Social distance can be considered as a component of socio-linguistic categories (status, age, sex, degree of intimacy, etc.) which together determine the whole degree of respectfulness with given speech situations, (Thomas, 1995:128). In other words, one feels close to someone if the person is dealt with him/her has the same "age, social class, occupation, sex, ethnicity, etc."

\section{Data and Methodology}

The selection of the tweets was first informed by discourse-centered online ethnography which combines the systematic observation of selected sites of online discourse. Based on this approach, eight different Twitter accounts specialized in racial humor were selected. All the tweets posed on these accounts were collected using vicinitas.io, which is an online software to track hashtags, tweets, and followers. This software makes the collected corpus eligible for more in-depth pragmatic investigation and insightful corpus-assisted analysis, such as word clouds, concordance, and collocation as shown in the table below. The methodological approach used in this paper is predominantly qualitative in nature, due to the international nature of the pragmatic phenomena explored in the thesis, i.e., rapport management. The analytical framework employed in the analysis will draw on triggering racial humor, as introduced by Spencer-Oatey (2008). The analysis, in this respect, will show four types of rapport: racial rapport enhancement, interpersonal rapport enhancement, racial rapport challenge, and interpersonal rapport challenge.

\section{Results}

Due to the interactional dynamics of posting and circulating racial jokes on Twitter, two different levels of interactions can be identified; namely: interpersonal and intercommunal (or social). Racial jokes can affect rapport across these two levels of interaction. The analysis below will explore how racial jokes on Twitter can potentially influence rapport between and among interlocutors.

\subsection{Racial Rapport Enhancement}

Racial rapport enhancement can be exemplified by the following tweet:

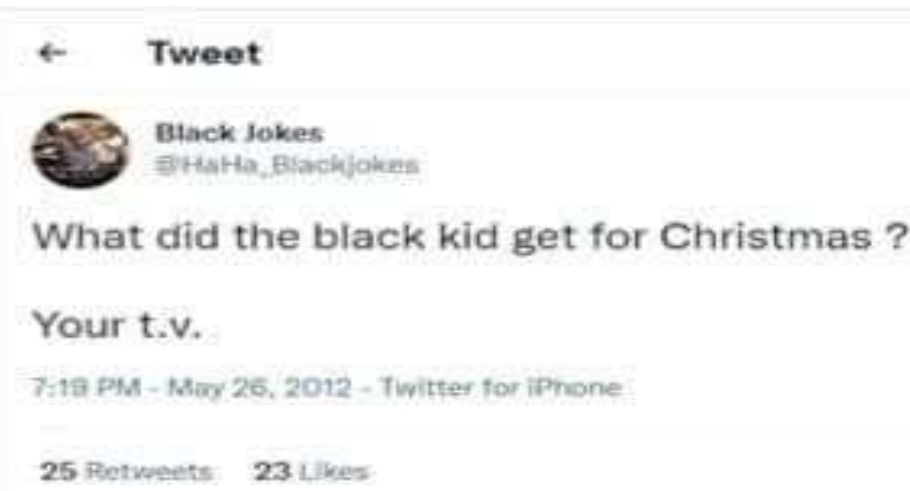

Figure (2) An Example of A Joke 
One might reasonably predict using expressions, like, black kid and Christmas function as deploying 'face-saving acts' as a device of making a face-supportive atmosphere. It could be merely a matter of achieving routine politeness behavior where it is predicted a matter of restoring relations in terms of face-saving behavior. From (im)politeness perspective, the racial joke involves closedrelation and solidarity to enhance the relationships among people as a whole. So, the phrase "Your t.v." is used to motivate domesticity and fellowship among followers. Such domesticity and fellowship are meant to give rise to politeness evaluation.

This illustration is verified by many scholars. For instance, Croom (2013: 191-194) and Pfister (2010: 1278) affirm that one of the interlocutors may strategically select to produce an utterance having the relevant slur in order to reinforce intimacy and in-group solidarity, under the presumption that the rapport between the interlocutors in this certain case is strong enough to overturn or neutralize what derogatory force the slur had originally interacted. Thus, the repetition of certain expressions via racial jokes does not necessarily communicate offensive connotations. It can be considered as a way of making close rapport among groups or associations.

It is worth mentioning that racial jokes take the social relationship into account when assessing the meaning of such jokes (i.e. the extent to which it may be understood as aggressive vs. bonding), little of it seems to take into consideration the impact of the situation. for instance, Brown and Levinson (1987: 320) 's description of 'joking' behavior within their theory of politeness is decontextualized and does not take account of the dynamism of interaction, despite it does provide a useful interpretive approach.

However, Brown and Levinson's (1987: 301) account permits for re-ranking of D (distance), but it cannot allow what would motivate such a strategy. A detailed discussion of racial jokes on Twitter shows that a sense of familiarity is made collaboratively through the usage of humor in order to perform personal face-saving goals. Thus, the parameter $D$ is re-ranked because of contextual considerations and achieved as a process of negotiation by followers. It seems that "an understanding of the context is crucial in explaining why interlocutors might collaborate in constructing an intimate relationship which would not otherwise exist", (ibid).

\subsection{Interpersonal Rapport Enhancement}

Interpersonal rapport management can be shown by investigating how the followers of a given account communicate with each other on Twitter. Consider the instance below:

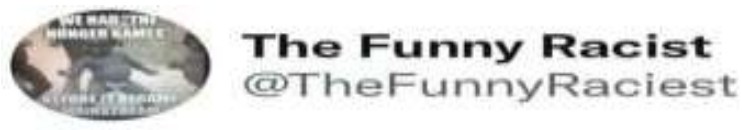

\section{Just downloaded a luis Suarez greatest moments video, it was only 3 mega bites}

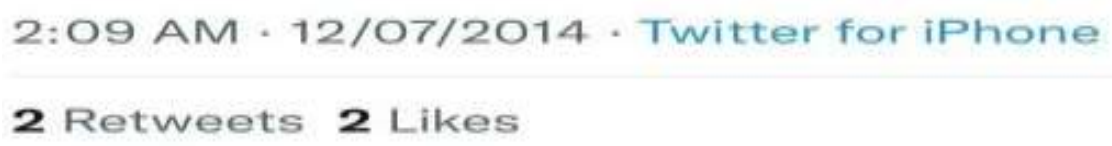

Figure (3) An Example of A Joke

The joke maker provides one of the famous footballers calling Luis Alberto Suárez Díaz who plays as a striker for Spanish club Atlético Madrid and the Uruguay national team. He utilizes two contradictory concepts that are greatest video moments and 3 mega bites. That is, the joke poster claims that although the video has little volume, it accounts for 3 mega bites denoting the greatest moments cost large volume. So, the commenter tries to state interpersonal rapport making funny with other followers of the concerned account. He obviously expresses his own friendship feelings towards the concerned player. Such racial joke represents the frame of one-to-one interaction that is active recipient, i.e. certain follower. Thus, people interact or frequently communicate with each other every day. This positive action starts by developing relationships with individuals. In relation to (im)politeness, the concerned joke, again, has closed-relation and solidarity to enhance the relationships among people as a whole.

In doing so, the joke poster insists on addressing his close followers informally with honorifics and the like. So, he may be strategically doing this in an attempt to signal their perception of the larger social distance throughout working in the opposite direction, and instead of speaking loosely or in accord with counter-culture values, an in-group speaker's usage of the relevant offends may be interpreted to operate "as a positively polite stressing of in-group knowledge and commonality of attitudes", (Brown \& Levinson, 1978: 28). 
This kind of close relationship between in-group followers and employing such colloquial conversational participants may usually (but not always) postulate that they will encounter minimal danger from face threats during their conversational interaction. Such an assumption is usually earned through respect, trust, and repeated interaction between friends or in-group followers. By virtue of this mutual interpreting, the employment of mock impoliteness or offense is used as a safe way for building rapport or facilitating social intimacy between followers, (Brown \& Levinson, 1978; Croom, 2011, 350). To illustrate, Goffman (1967: 86) explicates that conversational participants that are on "familiar terms with one another and need stand on little ceremony" are thereby freed to exchange mock insults in a non-threatening way for the purpose of poking fun at social circles where the insult is seriously utilized. Thus, if two Mexican American interlocutors, for example, both sense that they share a common culture or history and both interpret that neither of them involves any intention of offending the other, i.e. they are on suitable terms with each other and have gained mutual respect and trust through repeated friendly interactions.

\subsection{Racial Rapport Challenge}

Racial rapport challenge can be exemplified by the following tweet:

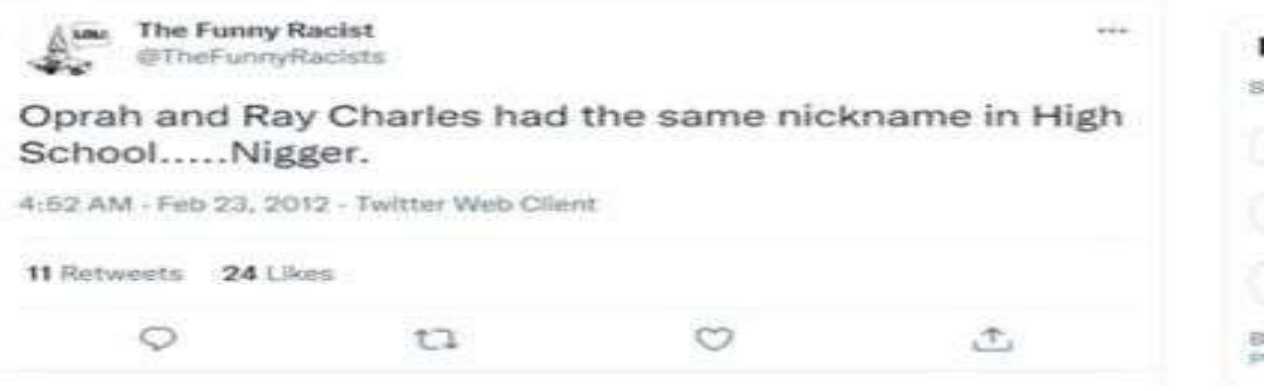

Figure (4) An Example of A Joke

The above tweet involves a racial joke derived from @TheFunnyRacists account. The joke poster tells followers that "Oprah and Ray Charles had the same nickname in High School.....Nigger" reflecting severely his own offensive emotions towards the AfricanAmerican community. He also points out that the frame of interaction naming one too many that are passive recipients, i.e. followers in general. That is, he impolitely informs all African-Americans who are actually nigger for the purpose of disparaging them. So, he utilizes two famous personalities, i.e. Oprah and Ray, not only to identify and refer to them specifically but also to refer generically, to all niggers as he suggested.

Moreover, the racial rapport challenging in the preceding joke is performed by using exemplars, i.e. Oprah and Ray Charles to impair the harmonies of the relationships among members of society. The joke maker intends to offend not only the concerned persons but the community to which they belong as a whole in order to make distinctions between individuals. He attempts to mock black people rather than white ones.

In other words, the joke poster communicates a snide remark against the black people, implicitly describing them as being outcast individuals, unlike white ones who are not offended by them. The reference to these two racial groups is established in terms of implicature. At a higher level, such implicature ascribes the unfavorable identity of the black people in America. As such, this criticism would be realized as inequality.

\subsection{Interpersonal Rapport Challenge}

As far as the current type of rapport management is concerned, the following example represents interpersonal rapport challenge extracted from the account of @TheFunnyRacists:

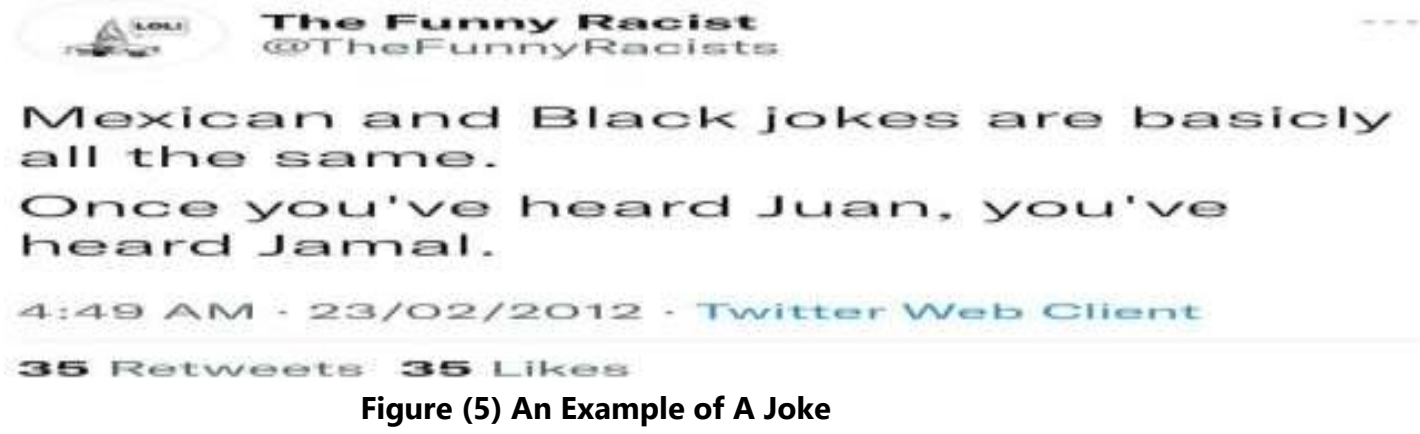


The above sample reflects an impression that the interaction conveys the frame of one to many. That is, the joke poster mocks from all the jokes that are related to both Mexicans and black people since, for him/her, they do not funny but common and normal. Two expressions exist in the preceding joke that is "Jamal" which indicates the black kids whereas "Juan" points out the Mexican kids. Thus, these names are ignored and challenge the individual rapport.

In relation to the impoliteness evaluation triggered by this joke, the current joke involves the implicational impoliteness formula. The main point issue with implicational impoliteness is that the comprehension is more implicit and thus involves more inferencing on the part of the target. For the impolite comprehension to find its marks, the target of the impoliteness should be able to encode or discern those characteristics within the wider pragmatic context, and it may not always be the case, particularly where the target has a different culture or language to the offender. The misconnecting of features motivate the force of the impolite messages because of the fact that:

"A conventionalized politeness formula can provide ... a reference point against which a conventionalized impoliteness formula or context predicting an impolite interpretation can be assessed. It alludes to the desired politeness context and in doing so provides a measure of the extreme distance by which the message flowing from the conventionalized impoliteness formula or context falls short, (Culpeper 2011:168).

This type of implicational impoliteness is based on a "convention-driven trigger" (Culpeper, 2016), which is represented by the expressions "Jamal" and "Juan". This interpretation is confirmed by Culpeper (2016: 439) who states that convention-driven impoliteness involves a mixture of politeness and impoliteness markers. The process of mixing characteristics of politeness with those of impoliteness can be confusing, but the context overrules one of the interpretations. Based on the conventionality of the offending act, many samples of convention-driven implicational impoliteness were found in the dataset, such as, "trespassing, pick cotton, shit, bucket, etc". These expressions regard convention-driven impoliteness since they carry negative and offensive connotations.

\section{Conclusions}

For racial rapport enhancing, the repetition of certain expressions via racial jokes does not necessarily communicate offensive connotations. It can be considered as a way of making close rapport among groups or associations. As for interpersonal rapport enhancing, the close relationship between in-group followers and employing such colloquial, conversational participants may usually (but not always) postulate that they will encounter minimal danger from face threats during their conversational interaction. Such an assumption is usually earned through respect, trust, and repeated interaction between friends or in-group followers. The aim of the current study was to re-visit the concepts of racial jokes, rapport as well as rapport management theory. It also aimed at reflecting how rapport management, i.e. whether racial or interpersonal, establishes relations among followers. However, the key findings are that racial rapport challenging using particular expressions denote offensive implications which function as making gaps among individuals. Additionally, the personal rapport challenge can be viewed through attacking relations in terms of conversational interaction of the followers. Thus, rapport orientation can either be one of enhancement, where there is a desire to strengthen or enhance harmonious relations, i.e. whether at the racial interpersonal level enhancement. Alternatively, rapport orientation can be one of a challenge when there is a desire to impair harmonious relations between the interlocutors i.e. whether at the racial or interpersonal level.

One of the contributions of the present study is to analyze the language utilized by joke makers showing the great roles that language functions in using human ideas and minds. The researcher highlights the implied notions and senses that they imply via their interaction. Another contribution is the researcher's attempt to investigate joke makers' speech based on the implicature and Gricean maxims. Such a model of analysis is followed for the purpose of studying the implied meanings of the racial jokes. It is revealed that the invisible meaning is beyond the literal usage of their speech. To confirm the findings of this study, the following are suggestions for future research:

1. Racial jokes in some dramatic texts: A pragmatic study.

2. Racial jokes in interviews: A pragmatic study.

3. Racial jokes in political debates: A pragmatic study. 


\section{References}

[1] Attardo, S. (2001). Humorous texts: A semantic and pragmatic analysis. Berlin: Mouton de Gruyter.

[2] Billings, M. (2005). "Comic racism and violence." Pp. 25-44 in Beyond a Joke: The Limits of Humour, edited by S. Lockyer and M. Pickering, New York: Palgrave Macmillan.

[3] Brown, P. and Levinson, S. (1987). Politeness: Some universals in language usage.

[4] -(1978). Universals in language usage: Politeness phenomena. In E. Goody (Ed.), Questions and Politeness: Strategies in Social Interaction 56310. Cambridge: Cambridge University Press.

[5] Byram, M. (2000). Encyclopedia of language teaching and learning. Cambridge: Cambridge University Press.

[6] Croom, A. M. (2013). How to do things with slurs: Studies in the way of derogatory words. Language and Communication, 33, $177-204$. http://dx.doi.org/10.1016/ j.langcom.2013.03.008Pfister, J. (2010). Is there a need for a maxim of politeness? Journal of Pragmatics, 42, 1266- 1282. http://dx.doi.org/10.1016/j.pragma. 2009.09.001

[7] Culpeper, J, Haugh, M. and Kádár, D. (2017). The Palgrave handbook of linguistic (im)politeness. Palgrave Macmillan: Macmillan Publishers Ltd.

[8] -(2011). Impoliteness: Using language to cause offense. Cambridge: Cambridge University Press.

[9] - (2016). Impoliteness strategies. In Alessandro Capone \& Jacob Mey (eds.), Interdisciplinary Studies in Pragmatics, Culture, and Society, 421 445. Switzerland: SpringerGoffman, E. (1967). Interaction ritual: Essays on face-to-face behavior. Harmon's worth: Penguin Books.

[10] Herring, S. (2007). A Faceted classification scheme for computer-mediated discourse. Bloomington: Indiana University. (http://www. languageatinternet.de, urn:nbn: de:0009-7-7611, ISSN 1860-2029)

[11] Holmes, J. (1995).Women, men, and politeness. London: Longman.

[12] Haines, R. (2014). Anonymity in computer-mediated communication: more contrarian ideas with less influence. https://link.springer.com /article/10.1007/s10726-012-9318-2 Liu, X. \& Allen, T. (2014). A study of linguistic politeness in Japanese. Open Journal of Modern Linguistic, 4,651-663.

[13] Hugh, M. and Bousfield, D. (2012). Mock impoliteness, jocular mockery, and jocular abuse in Australian and British English. Journal of Pragmatics, 44(9), pp.1099-1114.

[14] Locher, M. (2008). Impoliteness in language: Studies on its interplay with power in theory and practice. Berlin: Mouton De Gruyter.

[15] Ritchie, D. (2005). Frame-shifting in humor and irony. Metaphor and Symbol. 20.

[16] Shade, A.R. (1996). License to laugh: Humor in the classroom. Westport: Greenwood Publishing. Spencer-Oatey, H. (2002). Managing rapport in the talk: Using rapport-sensitive incidents to explore the motivational concerns underlying the management of relations. Journal of Pragmatics, 34, 529-545.

[17] - (2008). Face, (Im)politeness and Rapport. New York: MPG Books Ltd.

[18] - (2008). Culturally speaking culture, communication, and politeness theory. New York: MPG Books Ltd.

[19] Teng-Sheng, Alexander. "Can you judge a man by his friends? - enhancing spammer detection on the Twitter microblogging platform using friends and followers" Communications in Computer and Information Science Volume 54, 2010, pp 210

[20] Thomas, J. (1995). Meaning in interaction: An introduction to pragmatics. London: Longman.

[21] Willis, K. (2005). "Merry hell: Humour competence and social incompetence." Pp. 126-45 in Beyond a Joke: The Limits of Humour, edited by S. Lockyer and M. Pickering, New York: Palgrave Macmillan.

[22] Zabalbeascoa, P. (1996). "Humor in translation": An Intrdispline Available at www.academia.edu 323944

/Humor_and_Translation_an_Interdiscipline 